himself; it is thrown aside as soon as its use, which is solely a "pass" use, is over, and done with. Mr. Sidgwick says, with perfect fairness, that "the study of Greek is one thing, the knowledge of the Alcestis and the study of Mr. Bohn's translation of it another." That the University should have voted in this sense by sixty-three votes to forty, and expressed its desire to treat the mathematicians as entitled to a similar relief by twenty-seven to fourteen is a conclusive proof that the world moves even at Oxford. Many of those who are best acquainted with that University indeed declare that it is there only that it does move-at all events, that it is only there that it moves by "leaps and bounds," as British commerce used to do in the happy days of Mr. Gladstone's ministry! Certainly the votes of Oxford are often more liberal than those of London, and we cannot doubt that whenever the new Commission sets to work it will find as much impulse as obstruction from that great University. Of Cambridge itself it has ceased to be true to say that she maintains her usual attitude of magnificent repose. The universities are anxious to reform themselves if they only know how-the Commissioners will be happy to assist them if they only get power enough-and we may perhaps hope that a few "thinkers" may get something out of the reconstruction better than the very plain living with which their "high thinking" has hitherto been so commonly coupled.

\section{THE NEED OF MUSEUM REFORM}

${ }_{1} \mathrm{EW}$ of the many subjects now pressing themselves on the attention of the public are more important than that of museums, of the work which they are doing now in general education, and what they may reasonably be expected to do in the future. It is one which has occupied my mind for many years, and on which I venture to offer the following remarks.

The collecting instinct, the desire to accumulate what strikes the fancy, is so universal in all minds lifted above the satisfaction of the mere animal needs, that its absence is to be viewed as an infirmity or misfortune analogous to colour blindness or deafness. It is present in some form or another in most savages, and even in some birds, such as the bower-bird. It is based ultimately on the principle of curiosity combined with that of selfishness. Poor and much to be pitied is the man who has it not. The collections which result from it bear the stamp of the individual who makes them, and are as various as his tastes. They may be conveniently termed museum units, which, like molecules, have a tendency to coalesce into bodies of greaterorless size, and thus constitute museums. These are of high or low organisation according as the units keep or lose the stamp of the individual, and have been moulded into one living whole or are dissociated. They are highly organised and valuable if the parts are duly subordinated to each other and brought into a living relationship ; they are lowly organised and comparatively worthless if they remain as mere assemblages of units placed side by side without organic connection and without a common life.

Unfortunately in this country the provincial museums mostly belong to this latter class. It is that which takes sheltex for the most part in the top rooms of Mechanics Institutes and in the holes and corners of Free Libraries and Museums. In one instance which occurs to me, you see a huge plaster cast of a heathen divinity surrounded by fossils, stuffed crocouliles, minerals, and models of various articles such as Chinese junks. In another, a museum unit takes the form of a glass case containing a fragment of human skull and a piece of oatcake labelled "fragment of human skull very much like a piece of oatcake." In a third, wax models are exhibited of a pound weight of veal, pork, and mutton chops, cod fish, turnips, potatoes, carrots, and parsnips, which must have cost the value of the originals many times over, with labels explaining their chemical constitution, and how much flesh and fat they will make-just as if the public were macquainted with those articles of food, and required any information as to what these names really cover. Strangely enough this museum unit appears modern. In very many museums axt is not separated from natural history, nor from ethnology, and the cye of the beholder takes in at a glance the picture of a local worthy, a big fossil, a few cups and saucers, a piece of cloth from the South Seas, a war club or two, anci very possibly a mummy. The result of such an association as this, of articles which have no sort of relationship with the rest, is to convert the whole into rubbish, using the word in the Palmerstonian sense of being "matter in the wrong place." I do not mean to say that museums of this low order are useless. In default of better they are useful, just in proportion as they encourage the collecting instinct in the beholders. They may ultimately arrive at the higher stage of develonment. It is, however, a reproach to this country that museums of this low type should be found at this time, not merely in the smaller towns, but in some of the more important centres of population. They constitute a serious blot on our educational system, which we are striving to make as perfect as possible, since they are worse than 11seless for purposes of teaching. Instead of the natural harmony of things, they put before the mind a fortuitous concourse of atoms which is a very chaos.

While this state of things prevails largely in this country, there is no room for astonishment that museums of natural history hold the position which they do hold in the public mind. They are looked upon', as haunts of the mere specialist, and as altogether outside any scheme for the advancement of the higher studies. If they are sufficiently attractive to be visited, they are treated as places of amusement, in which "a happy day" may be spent, instead of places of instruction. They are sometimes avowedly arranged for that end. It rarely enters into any one's head that collections are as absolutely necessary for the advancement of natural history studies, as books to the literary student, though it is allowed on all hands that natural history is of great importance in general education. Until this anomaly be removed by the re-arrangement of the museums which require it, and the establishment of new ones, it is hopeless to expect the natural sciences to flourish as they should flourish, or for them to assume the importance which they deserve in the studies of this country. To the obvious remark that the fruits of English natural science are not worse than those of our neighbours, it may be answered that what has been done is the result of personal effort overcoming obstacles, and succeeding in spite of disadvantages. The fact that some men can swim does not render life-belts unnecessary for those who cannot. 
Well-arranged museums of every kind are now an educational necessity in every highly civilised state, and everywhere cxcepting in our own they are put on exactly the same footing as libraries. They are to be seen in nearly every town of any pretension on the Continent, and in cities, such as Turin, Bologna, Lyons, Brussels, and Hamburg, they exist on a scale which is only rivalled by those of I.ondon. In the United States, also, and in Australia, their value to society at Iarge is fully recognised. They are liberally supported and largely endowed. In no muscum out of Britain have I seen the chaos from which our own are now painfully and slowly emerging.

There are many highly organised muscums in Britain which perform their true function as repositories of knowledge, such as those at London and the Universities, those of Leeds, Livexpool, Bristol, Taunton, Exeter, Salisbury, and others. Their numbers must be largely increased if we are to hold our own in the race for knowledge with our neighbours on the Continent and our kinsmen in. Australia and America.

\section{W. BOXD DAWKINS}

FOSTER'S "TEXT-BOOK OF PHYSIOLOGY"

A Text.Book of Physiology. By M. Foster, M.A., M.D., F.R.S., Prelector of Physiology, and Fellow of Trinity College, Cambridge. (Macmillan, I877.)

7 HYSIOLOGY, like most other sciences, has been I making rapid strides within the last half century, and although scarcely yet to be classed among the exact sciences, the number of well-established facts which have been accumulated is not inconsiderable, and is in scveral cases sufficient to serve as a substantial foundation for the building up of more or less stable theories, and the enunciation cven of tolerably fixed laws. Consequently it is to-day no longer necessary to urge the importance of the cultivation of physiological science as the basis of rationa! medicine. Not only is this fully recognised by the medical profession but there are distinct indications that the public in general is beginning to appreciate the importance of a correct knowledge of the normal processcs which are going on within the body, preparatory to the recognition and cure of such deviations from the natural processes as constitute disease. And no wonder the science should be popular the object of which is to teach us how "we live and move and have our being !"

Students of physiology in this country have long needed an advanced text-book containing the leading facts and inferences of the science set forth at length and intelligibly, the statements and deductions which are less important or less clearly established being relegated to the background of small print, or even omitted altogether. The place of such a book was supplied in Germany by Hermann's " Grundriss der Physiologie," in every respect a model text-book, and one of which it is impossible to speak too highly; and it was hoped that the production last year of a translation of Hermann's work would meet the requirements of the English student. But whether simply from the fact of its being a translation or from other causes, certain it is that the book has not fulfilled the expectations which were entertained with regard to it. It is, therefore, a matter for sincere congratulation to physiologists that one in every respect so well qualified for the task as Dr. Michael Foster should have undertaken to provide what was so much needed in the way of a text-book, and also, it may fairly be added, to himself, that he should have brought the undertaking to so successful an issue.

Dr. Foster's aim in writing the book is best given in his own words :-

"I have striven to explain, in as clear and straightforward a manner as I could, the main facts and fundamental principles of physiological science. The student before whom things both new and old are tumbled out of the physiological treasury, without adequate critical appreciation of their respective values, is simply bewildered instead of being taught. . . . And it is the duty of the teacher to bring his pupil to that which is fixed and sure, without too much display or too much neglect of that which is uncertain and loose. .... A desire to contribute, as far as my powers will allow, to the development of physiology in the medical profession has been my guiding principle in writing the book."

The style of treatment and the mode of thought pursued throughout are characteristic of the author, and serve to indicate the originality of the book, always one of the chief merits of a work of this sort. It is often thought that a scientific text-book need be little more than a museum of facts and opinions, carefully arranged and neatly labelled, to enable them the more readily to be "got up" by the student, in order that he may be able to satisfy an examiner with a narration of whatever has been stated or conjectured about any particular subject. Were this the case, the making of a text-book would be a mexe natter of scissers and paste-brush, and the task could be performed by any one who was capable of reading the language of the science. That the idea is a wrong one is so self-evident that it would be waste of words to delay in refuting it. Even an elementary textbook is never so well done as when it is taken in hand by one who is a master in the science. There is a wellknown instance in this particular science of physiology, and, in fact, it is to Huxley's "Lessons" that Dr. Foster wishes his book to be regarded as the sequel.

An indication of the original character of the book before us is to be found in the fact that it is not throughout equal. All the subjects are well done, but some are better treated than others, a result to be expected from the very extended nature of the science. No one-not even a Helmholtz-can pretend to an intimate personal acquaintance with all the branches of so ramified a science, and it is casting no slur upon the rest of the work to single out a section here and there, characterised by the especial clearness with which the known facts are stated and the phenomena are discussed and explained. The articles on the coagulation of the blood and on gastric and pancreatic digestion, and the chapter on the spinal cord, may be especially mentioned as illustrations of this.

Another and a more prominent indication of originality is occasionally met with in the descriptions of observable phenomena, facts being here and there noticed which are obviously the result of personal observation, and which have not hitherto so far as we are aware, been noted down. Thus in describing the phenomena of the heart's beat in mammals the contraction of the auricles is stated to be preceded by 2 peristaltic contraction of all the 